\title{
Macrocarpane, a New Sesquiterpene Skeleton from the Leaves of Porcelia macrocarpa
}

\author{
Mariana H. Chaves ${ }^{a}$, João Henrique G. Lago ${ }^{*, b}$ and Nídia F. Roque ${ }^{b, c}$ \\ ${ }^{a}$ Instituto de Química, Universidade Federal do Piauí, Campus Ininga, 64049-550 Teresina - PI, Brazil \\ ${ }^{b}$ Instituto de Química, Universidade de São Paulo, CP 26077, 05513-970 São Paulo - SP, Brazil \\ ${ }^{c}$ Instituto de Química, Universidade Federal da Bahia, 40170-290 Salvador - BA, Brazil
}

\begin{abstract}
O óleo volátil e o extrato hexânico das folhas de Porcelia macrocarpa (Warm.) R.E. Fries, Annonaceae, foram submetidos a fracionamentos cromatográficos. Nove sesquiterpenos ( $\alpha$-cubebeno, $\alpha$-copaeno, germacreno-D, biciclogermacreno, $\gamma$-cadineno, $\delta$-cadineno, espatulenol, globulol e cis-cubenol) além de um diterpeno (fitol) foram identificados no óleo volátil, correspondendo a $83.1 \%$ (em massa) do total de constituintes. Dois sesquiterpenos (espatulenol e macrocarp-11(15)en-8-ol), o último apresentando um novo esqueleto estrutural, um diterpeno (fitol), além de dois esteróides (sitosta-5,25-dien-3 $\beta$-ol e sitosta-5,22,25-trien-3 $\beta$-ol), foram isolados do extrato hexânico. As substâncias foram caracterizadas através de experimentos de $\mathrm{RMN}$ de ${ }^{1} \mathrm{He} \mathrm{e}^{13} \mathrm{C}$, incluindo análise bidimensional, além de espectrometria de massas.
\end{abstract}

The volatile oil and the hexane extract from the leaves of Porcelia macrocarpa (Warm.) R.E. Fries, Annonaceae, were submitted to chromatographic separations. Nine sesquiterpenes $(\alpha$-cubebene, $\alpha$-copaene, germacrene-D, bicyclogermacrene, $\gamma$-cadinene, $\delta$-cadinene, spathulenol, globulol and cis-cubenol) and one diterpene (phytol) were identified in the volatile oil (83.1\% in weight). Two sesquiterpenes (spathulenol and macrocarp-11(15)-en-8-ol), the latter with a novel skeleton, one diterpene (phytol) and two steroids (sistosta-5,25-dien-3 $\beta$-ol and sitosta-5,22,25-trien-3 $\beta$-ol) were isolated from the hexane extract. These compounds were characterized by ${ }^{1} \mathrm{H}$ and ${ }^{13} \mathrm{C}$ NMR spectroscopy, including bidimensional analysis and mass spectrometry.

Keywords: macrocarpane, spathulenol, steroids, sesquiterpenes, Porcelia macrocarpa

\section{Introduction}

The chemical constitution of Porcelia macrocarpa was described in four previous papers. In the first one, acetogenins from seeds were reported. ${ }^{1}$ Two other papers report the presence of amides, lignanamides and alkaloids from the branches. ${ }^{2,3}$ The polar constituents, such as aminoacids, trimethylamonium salts and glycosilated flavonoids were also described. ${ }^{4}$ From our previous studies with $P$. macrocarpa we describe herein the identification of nine sesquiterpenes and one diterpene in the volatile oil and two sesquiterpenes, one diterpene and two steroids in the hexane extract, both from the leaves. The ${ }^{1} \mathrm{H}$ and ${ }^{13} \mathrm{C}$ NMR data of 10, including bidimensional analysis, showed a novel sesquiterpene skeleton, which was denominated macrocarpane.

\footnotetext{
* e-mail: joaolago@iq.usp.br
}

\section{Results and Discussion}

The hexane extract of the leaves of $P$. macrocarpa was submitted to chromatographic separations to give two sesquiterpenes: spathulenol (7) and macrocarp-11(15)-en8-ol (10), one diterpene: phytol (11) and two steroids: sistosta-5,25-dien-3 $\beta$-ol (12) and sitosta-5,22,25-trien-3 $\beta$ ol (13). The sesquiterpene 7, the diterpene $\mathbf{1 1}$ and the steroids 12 and 13 were identified by analysis of their ${ }^{1} \mathrm{H}$ and ${ }^{13} \mathrm{C}$ NMR data and comparison with data described in the literature. ${ }^{5-8}$

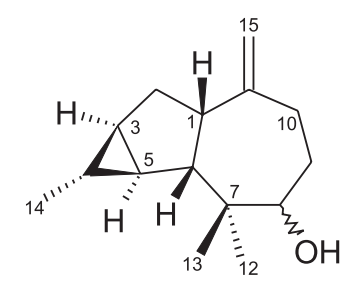


The EIMS spectrum of $\mathbf{1 0}$ showed the molecular ion peak at $m / z 220 \mathrm{Da}$. The ${ }^{13} \mathrm{C}$ NMR spectra (BBD and DEPT $135^{\circ}$ ) displayed fifteen signals refering to three methyls, four methylenes, six methines, as well as two quaternary carbon atoms, suggesting the occurrence of an oxygenated sesquiterpene with molecular formula $\mathrm{C}_{15} \mathrm{H}_{24} \mathrm{O}$. The signals at $\delta 146.0(\mathrm{C})$ and $\delta 105.7\left(\mathrm{CH}_{2}\right)$ were indicative of an exocyclic methylenic group, and the single signal at the carbinolic region $[\delta 77.4(\mathrm{CH})]$ confirms the presence of one hydroxyl group in the molecule of $\mathbf{1 0}$.

The ${ }^{1} \mathrm{H}$ NMR spectrum showed three methyl groups at $\delta 0.79(\mathrm{~s}), \delta 0.93$ (s) and $\delta 0.93(\mathrm{~d}, J 3.0 \mathrm{~Hz})$, the latter being linked to a methinic carbon atom. This spectrum also showed a signal at $\delta 0.51(\mathrm{~m})$, suggesting the presence of a cyclopropane ring in the structure of 10. The observation of a double-multiplete at $\delta 48.6$, in the gated ${ }^{13} \mathrm{C}$ NMR spectrum with $J 163 \mathrm{~Hz}$, characteristic of three member ring, ${ }^{9}$ confirms the cyclopropane ring in the molecule. The HMQC spectrum showed long-range correlations between carbons and hydrogens (Table 1). These results associated with those showed in ${ }^{1} \mathrm{H}^{-}{ }^{1} \mathrm{H} \mathrm{COSY}$ spectrum indicated the connectivities in the molecule, and suggested a decahydroazulene derivative with a cyclopropane ring. The mutual long range coupling between the signals at $\delta 1.48(\mathrm{H}-1)$ and $\delta 4.82(\mathrm{H}-15), \delta$ $2.28(\mathrm{H}-10)$ and $\delta 1.29(\mathrm{H}-5)$, the latter being a W coupling, corroborates the suggested structure and indicated the $\beta$ orientation to cyclopropane ring. This spectrum also showed the coupling between the hydrogens at C-9 and those at C-10 and C-8; thus, the two methyl groups should be at $\mathrm{C}-7$. The presence of these groups interrupted the
${ }^{1} \mathrm{H}-{ }^{1} \mathrm{H}$ connectivities in the seven member ring. Therefore, the cyclopropane group could only be at the five-carbon ring. The mutual coupling observed among the signals at $\delta 0.51(\mathrm{H}-4)$ and $\delta 1.29(\mathrm{H}-5)$, and $\delta 1.18(\mathrm{H}-3)$ located the cyclopropane ring between C-3/C-5. This situation was corroborated by the correlations between $\mathrm{H}-3 / \mathrm{H}-2$ and $\mathrm{H}-$ $3 / \mathrm{H}-6$, observed in the ${ }^{1} \mathrm{H}-{ }^{1} \mathrm{H}$ COSY spectrum. HMBC long range correlations confirm the proposed structure. The small coupling constants of $\mathrm{H}-1\left(\mathrm{~W}_{1 / 2}=8 \mathrm{~Hz}\right)$ indicated a cis ring junction between the five and seven member rings. The chemical shift of methyl group at C-4 ( $\delta$ 21.8) suggested the presence of this group at a position, free of $\delta$ interactions. This sesquiterpenic skeleton has not been described in the literature yet, and was denominated macrocarpane. Therefore, the structure of $\mathbf{1 0}$ was defined as macrocarp-11(15)-en-8-ol.

The biosynthetic pathway proposed to $\mathbf{1 0}$ should involve a himachalane derivative which was not detected in this study, but has been isolated from Ferula latipinna (Umbelliferae), ${ }^{10}$ which could be formed by cyclization of bicyclogermacrene (Figure 1). In the volatile oil, the absence of $\mathbf{1 0}$ and the reduced amount of $\mathbf{7}(3.0 \%)$ could be explained by the predominance of germacrene-D $(37.8 \%)$ and bicyclogermacrene $(27.5 \%)$. In the hexane extract, these sesquiterpenes were not detected, indicating that $\mathbf{7}$ and $\mathbf{1 0}$ should be formed from $\mathbf{4},{ }^{11}$ corroborating the proposed biosynthetic pathway.

The volatile oil from the leaves of $P$. macrocarpa was submitted to chromatographic separation and the fractions obtained were analysed by GC. ${ }^{12}$ The sesquiterpenes $\mathbf{3}, \mathbf{4}$, $\mathbf{7 , 8}$ and $\mathbf{9}$ and the diterpene $\mathbf{1 1}$ were characterized as the

Table 1. ${ }^{1} \mathrm{H}$ and ${ }^{13} \mathrm{C}$ NMR data for sesquiterpene $10\left(500\right.$ and $125 \mathrm{MHz}, \delta, \mathrm{CDCl}_{3}$ )

\begin{tabular}{|c|c|c|c|c|}
\hline & ${ }^{1} \mathrm{H}-{ }^{1} \mathrm{H}$ coupling & ${ }^{1} \mathrm{H}^{\mathrm{a}}$ (multiplicity, $J / \mathrm{Hz}$ ) & ${ }^{13} \mathrm{C}^{\mathrm{b}}$ & НМBC \\
\hline 1 & $1.29,4.82,2.28$ & $1.48(\mathrm{~m})$ & 57.8 & $1.96,4.79, \quad 4.82$ \\
\hline \multirow[t]{2}{*}{2} & $1.96,1.18$ & $1.02(\mathrm{dd}, 12.0 ; 4.0)$ & 42.7 & \\
\hline & $1.02,1.18$ & $1.96(\mathrm{dd}, 12.0 ; 7.0)$ & & \\
\hline 3 & $0.93,1.96,1.29,1.02,0.51$ & $1.18(\mathrm{~m})$ & 24.6 & \\
\hline 4 & $0.93,1.18,1.29$ & $0.51(\mathrm{~m})$ & 48.6 & 0.93 \\
\hline 5 & $1.48,1.18$ & $1.29(\mathrm{~m})$ & 24.4 & \\
\hline 6 & $0.51,0.79,1.18$ & $0.93($ br dd, $10.0 ; 4.0)$ & 32.4 & 0.93 \\
\hline 7 & - & - & 59.1 & 0.79 \\
\hline 8 & $1.75,1.43$ & $3.51(\mathrm{dd}, 12.0 ; 5.5)$ & 77.4 & 0.79 \\
\hline \multirow[t]{2}{*}{9} & $3.51,2.28,2.02,1.75$ & $1.43(\mathrm{dq}, 12.0 ; 5.5)$ & 31.1 & \\
\hline & $2.02,1.43,3.51,2.28$ & $1.75(\mathrm{td}, 12.0 ; 5.5)$ & & \\
\hline \multirow[t]{2}{*}{10} & $2.28,1.75,1.43,4.79$ & $2.02(\mathrm{ddd}, 14.0 ; 12.0 ; 5.5)$ & 34.0 & 4.79 \\
\hline & $2.02,1.43,1.75,1.48$ & $2.28($ br dd, $14.0 ; 5.5)$ & & \\
\hline 11 & - & - & 146.0 & \\
\hline 12 & 0.93 & $0.79(\mathrm{~s})$ & 13.8 & \\
\hline 13 & - & $0.93(\mathrm{~s})$ & 21.9 & 0.93 \\
\hline 14 & 0.51 & $0.93(\mathrm{~d}, 3.0)$ & 21.8 & \\
\hline \multirow[t]{2}{*}{15} & 1.48 & $4.82(\mathrm{br} \mathrm{s})$ & 105.7 & \\
\hline & 2.02 & 4.79 (br s) & & \\
\hline
\end{tabular}

${ }^{\mathrm{a}} \ldots 500 \mathrm{MHz} ;{ }^{\mathrm{b}} \ldots 125 \mathrm{MHz}$. 


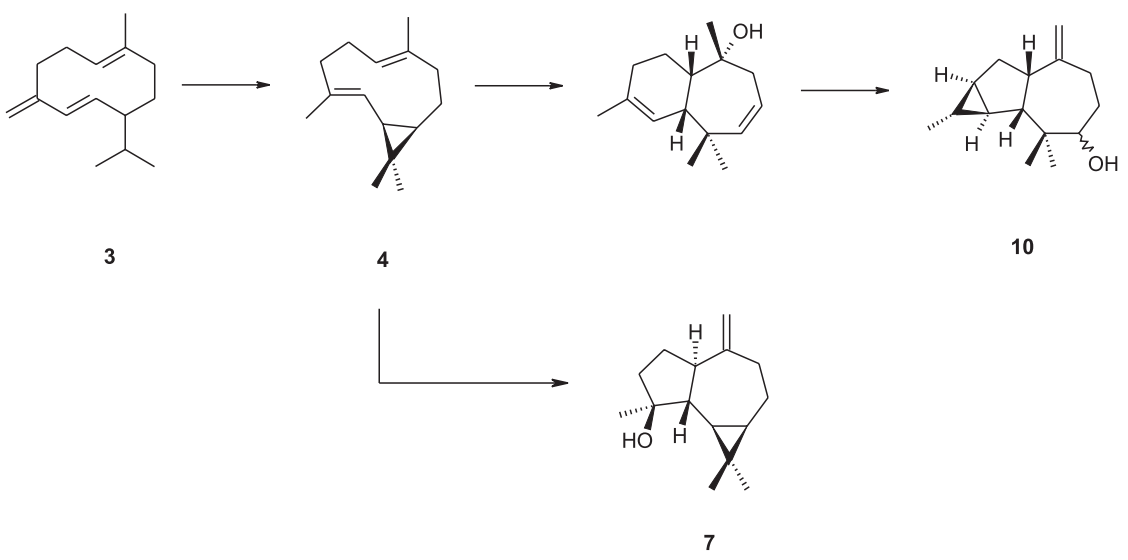

Figure 1. Hypothetic biosynthetic pathway of sesquiterpenes $\mathbf{7}$ and $\mathbf{1 0}$ from $\mathbf{3}$ and $\mathbf{4}$.

main compounds in mixtures by analysis of their ${ }^{1} \mathrm{H}$ and ${ }^{13} \mathrm{C}$ NMR spectra. The comparison with the literature values confirmed the proposed structures ${ }^{5,13-15}$. Additionally, the crude volatile oil was submitted to analysis by GC/MS. The sesquiterpenes $\mathbf{1}, \mathbf{2}, \mathbf{5}$ and $\mathbf{6}$ were identified. This analysis confirms the identification of the sesquiterpenes $\mathbf{3}, \mathbf{4}$ and, 7, and the diterpene 11, which were characterized by NMR. Using this methodology, which is a combination of three spectrometric techniques (NMR, GC, GC/MS), nine sesquiterpenes, and one diterpene ( $83.1 \%$ in weight) were identified in the volatile oil (Table 2).

Table 2. Chemical constituition of the crude volatile oil from leaves of $P$. macrocarpa

\begin{tabular}{lrrrcc}
\hline component & $\mathrm{RR}_{\mathrm{t}}$ & $\mathrm{RI}$ & $\begin{array}{r}\text { percentage } \\
\text { identification } \\
\text { GC/MS }\end{array}$ & NMR \\
\hline$\alpha$-cubebene (1) & 562 & 1351 & 3.1 & $\mathrm{X}$ & \\
$\alpha$-copaene (2) & 581 & 1376 & 1.8 & $\mathrm{X}$ & \\
germacrene-D (3) & 712 & 1480 & 37.8 & $\mathrm{X}$ & $\mathrm{X}$ \\
bicyclogermacrene (4) & 734 & 1496 & 27.5 & $\mathrm{X}$ & $\mathrm{X}$ \\
$\gamma$-cadinene (5) & 745 & 1513 & 1.4 & $\mathrm{X}$ & \\
$\delta$-cadinene (6) & 769 & 1524 & 2.0 & $\mathrm{X}$ & \\
spathulenol (7) & 849 & 1576 & 3.0 & $\mathrm{X}$ & $\mathrm{X}$ \\
globulol (8) & 857 & 1592 & 1.6 & & $\mathrm{X}$ \\
cis-cubenol (9) & 954 & 1668 & 1.9 & & $\mathrm{X}$ \\
phytol (11) & 1518 & 2114 & 3.0 & $\mathrm{X}$ & $\mathrm{X}$ \\
\hline
\end{tabular}

\section{Experimental}

\section{Plant material}

All the leaves of P. macrocarpa (Warm.) R.E. Fries were collected from the same specimen, in March 1992 (hexane extract), and in December 2000 (volatile oil) at the Jardim Botânico of São Paulo State. A voucher specimen has been deposited in the herbarium of the Instituto Botânico, São Paulo, Brazil under reference SP76791.

\section{Extraction and isolation of the compounds}

Dried powdered leaves (750 g) of P. macrocarpa were extracted with hexane three times at room temperature. The concentrated hexane extract was partitioned between $\mathrm{MeOH} / \mathrm{H}_{2} \mathrm{O}(9: 1, \mathrm{v} / \mathrm{v})$ and hexane. The hexanic part $(10 \mathrm{~g})$ was submitted to precipitation with $\mathrm{MeOH}$ from which were obtained the waxy material $(9 \mathrm{~g})$, and the $\mathrm{MeOH}$ soluble material $(1 \mathrm{~g})$. The $\mathrm{MeOH} / \mathrm{H}_{2} \mathrm{O}$ phase $(6 \mathrm{~g})$ and the $\mathrm{MeOH}$ soluble material $(1 \mathrm{~g})$ were pooled together, chromatographed on silica gel column and eluted with increasing amounts of EtOAc in hexane, from which were obtained four groups (I-IV), after TLC on silica gel analyses. The group I $(351 \mathrm{mg})$ was submitted to flash chromatography on silica gel and eluted with hexaneEtOAc (6:4, v/v) yielding 7 (77 mg). Group II $(720 \mathrm{mg})$ was methylated with diazomethane, submitted to flash chromatography on silica gel and eluted with hexaneEtOAc (97:3, v/v) giving two mixtures A (359 mg), and B (30 mg). The ${ }^{1} \mathrm{H}$ NMR spectrum of A showed the occurrence of fatty acid esters. Fraction B was applied to a Sephadex LH-20 column and eluted with hexane- $\mathrm{CH}_{2} \mathrm{Cl}_{2}(1: 4, \mathrm{v} / \mathrm{v})$ to yield $11(10 \mathrm{mg})$. Group III $(483 \mathrm{mg})$ was submitted to flash chromatography on silica gel and eluted with hexane$\left[\mathrm{CH}_{2} \mathrm{Cl}_{2}-\mathrm{MeOH}(98: 2, \mathrm{v} / \mathrm{v})\right](6: 4, \mathrm{v} / \mathrm{v})$ to give two mixtures $\mathrm{C}(30 \mathrm{mg})$ and D $(200 \mathrm{mg})$. Mixture C was comprised of two steroids (12 and 13). Mixture D was applied to a Sephadex LH-20 column and eluted with hexane- $\mathrm{CH}_{2} \mathrm{Cl}_{2}$ $(1: 4, \mathrm{v} / \mathrm{v})$ to give a mixture of one sesquiterpene and steroidal material. The purification by prep. TLC on silica gel with $15 \%$ of $\mathrm{AgNO}_{3}$ [hexane-EtOAc $\left.(6: 4, \mathrm{v} / \mathrm{v})\right]$ yielded 10 (15 mg).

The fresh plant material $(2250 \mathrm{~g})$ was hydrodistilled 
using a Clevenger type apparatus to give the crude volatile oil $(735 \mathrm{mg}$; yield $0.03 \%)$. Part of this material $(500 \mathrm{mg}$ ) was submitted to flash chromatography on silica gel and eluted with $\mathrm{CH}_{2} \mathrm{Cl}_{2}$ and $\mathrm{CH}_{2} \mathrm{Cl}_{2}-\mathrm{MeOH}$ (95:5 and 9:1) affording mixtures containing $\mathbf{1}+\mathbf{3}+\mathbf{4}(\mathrm{fr} 4,137 \mathrm{mg}), \mathbf{3}+$ 4 (fr 6, $25 \mathrm{mg}$ ), 11 (fr 34, $16 \mathrm{mg}$ ), 7 (fr 38, $12 \mathrm{mg}$ ), $\mathbf{8}+\mathbf{9}$ (fr $39,52 \mathrm{mg}$ ). The remaining part of the crude volatile oil was subjected to analysis by GC/MS to identify the sesquiterpenes $\mathbf{1}, \mathbf{2}, \mathbf{5}$ and $\mathbf{6}$.

\section{General}

Silica gel 60 (Merck) was used for chromatography: 63-200 $\mu \mathrm{m}$ for CC, 40-63 $\mu \mathrm{m}$ for flash chromatography, $\mathrm{PF}_{254}(5-45 \mu \mathrm{m})$ for preparative TLC. IR spectra were obtained as $\mathrm{KBr}$ pellets in a Perkin-Elmer Infrared Spectrometer model 1750. Sephadex LH-20 (Sigma) was used for molecular exclusion chromatography. NMR spectra were recorded at 300 and $500 \mathrm{MHz}$ for ${ }^{1} \mathrm{H}$ and 75 and $125 \mathrm{MHz}$ for ${ }^{13} \mathrm{C}$ on Brüker DPX-300 and DRX-500 spectrometers using $\mathrm{CDCl}_{3}$ as solvent and internal standard. The GC analysis was performed in a Hewlett-Packard 5890 series II (using helium as carrier gas) equipped with a FID detector and a capillary column HP-5, crosslinked 5\% phenyl in $95 \%$ methyl silicone (30 m x $0.32 \mathrm{~mm}$, film thickness $0.25 \mu \mathrm{m}$ ) with a automatic injector (HP 7673) and an electronic integrator (HP 3396A). The temperature programming was from isothermal $100^{\circ} \mathrm{C}$ for $2 \mathrm{~min}, 100^{\circ}$ $240{ }^{\circ} \mathrm{C}$ at $5^{\circ} \mathrm{C} \cdot \mathrm{min}^{-1}$, then isothermal at $240{ }^{\circ} \mathrm{C}$ for $5 \mathrm{~min}$. The (FID) injector and detector temperatures were $180^{\circ} \mathrm{C}$ and $260^{\circ} \mathrm{C}$, respectively. The GC/MS analyses were carried out in an EIMS 70 eV Hewlett-Packard HP-5973 coupled with a Hewlett-Packard HP-6890 with a DB-50 column ( $30 \mathrm{~m}$ x $0.25 \mathrm{~mm}$, film thickness $0.25 \mu \mathrm{m}$ ) using the same temperature programming conditions describe above. The identification of the compounds was done by comparing retention indices (determined relatively to the retention times of a series of $n$-alkanes) and mass spectra to those of authentic samples.

Macrocarp-11(15)-en-8-ol (10): colourless oil. IR (KBr) $v_{\max } \mathrm{cm}^{-1}: 3402(\mathrm{OH}), 3108$ (cyclopropane ring), $2945(\mathrm{C}-$ $\mathrm{H}), 1637\left(>\mathrm{C}=\mathrm{CH}_{2}\right), 919,888$. EIMS $(70 \mathrm{eV}) \mathrm{m} / \mathrm{z}$ (rel. int.) $220[\mathrm{M}]^{+}(58), 202\left[\mathrm{M}-\mathrm{H}_{2} \mathrm{O}\right]^{+}(7), 187\left[\mathrm{C}_{14} \mathrm{H}_{19}\right]^{+}(17), 177$ $\left[\mathrm{C}_{12} \mathrm{H}_{17} \mathrm{O}\right]^{+}(22), 159\left[\mathrm{C}_{12} \mathrm{H}_{15}\right]^{+}(100), 145(24), 135(16)$, 133(27), 131(32), 121(16), 119(32), 117(30), 109(28),
107(23), 105(48), 95(14), 93(44), 91(55), 81(23), 79(32), 77(31), 69(13), 67(32), 65(14), 57(12), 55(36), 53(22). ${ }^{1} \mathrm{H}$ and ${ }^{13} \mathrm{C}$ NMR: see table 1.

\section{Acknowledgements}

The authors are grateful to Dra. Maria Claudia Marx Young from Instituto de Botânica/SMS for the plant material provision. This work was supported by CAPES, CNPq and FAPESP.

\section{References}

1. Chaves, M.H.; Roque, N.F.; Phytochemistry 1997, 44, 523.

2. Chaves, M.H.; Roque, N.F.; Phytochemistry 1997, 46, 879.

3. Chaves, M.H.; Santos, L.A.; Lago, J.H.G.; Roque, N.F.; J. Nat. Prod. 2001, 64, 240.

4. Chaves, M.H.; Freitas, A.; Roque, N.F.; Cavalheiro, A.J.; Quim. Nova 2000, 23, 307.

5. Iwabuchi, H.; Yoshikura, M.; Kamisako, W.; Chem. Pharm. Bull. 1989, 37, 509.

6. Rahman, A.; Ahmad, V.U.; ${ }^{13}$ C NMR of Natural Products, Plenum Press: New York, 1992.

7. Ahmad, V.U.; Aliya, R.; Perveen, S.; Shameel, M.; Phytochemistry 1992, 31, 1429.

8. Chaves, M.H.; PhD Thesis, Universidade de São Paulo, Brazil, 1996.

9. Gil, V.M.S.; Geraldes, C.F.G.C.; Ressonância Magnetica Nuclear, Fundação Calouste Gulbenkian: Lisboa, 1987.

10. Gonzales, A.G.; Bermejo, J.; Diaz, J.G.; Arancibia, L.; De Paz, P.P.; J. Nat. Prod. 1988, 51, 1140.

11. Toyota, M.; Koyama, H.; Mizutani, M.; Asakawa, Y; Phytochemistry 1996, 5, 1347.

12. Brochini, C.B.; Núñez, C.V.; Moreira, I.C.; Roque, N.F.; Chaves, M.H.; Martins, D.; Quim. Nova 1999, 1, 37.

13. Randriamiharisoa, R.; Gaydou, E.M.; Faure, R.; Bianchini, J.P.; Mag. Res. Chem. 1986, 24, 275.

14. Toyota, M.; Nagashima, F.; Fukuyama, Y.; Honda, S.; Asakawa, Y.; Phytochemistry 1988, 27, 3317.

15. Faure, R.; Ramanoelina, A.R.P.; Rakotonirany. O.; Bianchini, J.P.; Gaydou, E.M.; Mag. Res. Chem. 1991, 29, 969.

Received: November 1, 2001 Published on the web: October 29, 2002

FAPESP helped in meeting the publication costs of this article. 